\title{
Coflex Dynamic Distraction Stabilization Device for Lumbar Degenerative Diseases
}

\author{
Mohamed Mohi Eldin
}

1.

Corresponding author: Mohamed Mohi Eldin, mmohi63@yahoo.com

\begin{abstract}
Aim of the study: The purpose of this study was to assess the safety and effectiveness of the Coflex Dynamic Distraction Stabilization (DDS) device in treating patients with degenerative diseases of the lumbar spine (DDLS), especially lumbar canal stenosis (LCS), to confirm its indications for implantation and to evaluate
\end{abstract} the clinical outcomes of patients.

Material \& Methods: Our study is part of a multi-centre prospective, case-controlled study in Egypt to determine the safety and efficacy of minimally invasive spinal procedures; of these, the Coflex implant, a functionally dynamic U-shaped titanium interspinous implant, was included in the present study. From June 2008 until July 2013, we treated 42 patients with this Coflex procedure. Median follow-up was 22.5 months. At the time of follow-up, all patients completed questionnaires and underwent clinical examination and spinal radiography.

Results: A significant number of patients showed pain relief. Preoperatively, 30/42 (71\%) patients complained of moderate or severe low back pain (LBP). Postoperatively, the LBP in six (14\%) patients did improve, 24 (57\%) even showed no low back pain anymore. Mean preoperative walking distance was $<1000 \mathrm{~m}$ in 36 (86\%) patients. Postoperatively, all 42 (100\%) patients could walk >1000m. Significant pain relief (> $50 \%$ ) in months was calculated. Radiological results showed that endplate angles when were acute preoperatively, always became less acute postoperatively, and the foraminal height always increased. Segmental range of motion (ROM) showed maintenance of the dynamic movements at the operated level. Disc height showed significant changes after the procedure in both anterior and posterior disc heights.

Conclusion: The data provided has demonstrated that the Coflex implant provides pain relief for patients with indicated DDLS cases. The most common indications for implantation were spinal stenosis and spinal stenosis with lumbar disc herniation. There were no device-related complications. Using Coflex is a safe option in the selection of instrumentation for spinal stabilization.

Received 12/27/2013 Review began 12/30/2013 Published 01/02/2014

๑) Copyright 2014 Mohi Eldin. This is an open access article distributed under the terms of the Creative Commons Attribution License CC-BY 3.0., which permits unrestricted use, distribution, and reproduction in any medium, provided the original author and source are credited.
Categories: Pain Management, Neurosurgery

Keywords: canal stenosis, coflex, dynamic, lumbar

\section{Introduction}

The most severe primary spinal degenerative changes are found in the lumbar spine region. Degenerative diseases of the lumbar spine (DDLS) are among the most common clinical entities. DDLS affects the intervertebral discs, the vertebral endplates, the facet joints, and the intervertebral posterior ligaments. These changes are well-known and often grouped under the broad definition of vertebral arthrosis, secondary to degeneration of the ligaments and cartilage. From a functional standpoint, the first event is hypermobility of the joints due to weak ligaments and the no longer perfect coaptation of the joint surfaces. These changes continue on to morphological changes causing narrowing of the affected segment and its exit foramina, and ending in some form of degenerative instability [1-9].

In our study, the Coflex ${ }^{\circledR}$ Dynamic Distraction Stabilization (DDS) Device (Paradigm Spine GmbH, Germany) offered both dynamic stabilization and interlaminar orientation. It is indicated in patients whose symptoms are exacerbated in extension and relieved in flexion. Implanted between the spinous processes and reaching down to the laminar level, the Coflex ${ }^{\circledR}$ DDS device is functionally dynamic, being compressible in extension and limiting flexion, with increased rotational stability; the center of rotation being close to the spinal canal. Protection of posterior elements through stress reduction on facet joints and maintenance of foraminal height is also offered. More advantages of the device include its ease of use, in a less invasive, tissue-sparing procedure with precise application of the device. We consider degenerative lumbar stenosis as the main indication for implanting the dynamic interspinous Coflex device [10-20].

This study is a multi-center, prospective case-controlled study designed to assess the safety and effectiveness of the Coflex ${ }^{\circledR}$ DDS Device in treating patients with DDLS, especially LCS, to confirm its indications for implantation and to evaluate the clinical outcomes of patients. We intend to understand the changes in the disc height as well as segmental dynamic movement ability before and after Coflex ${ }^{\circledR}$ 
implantation in patients with symptomatic lumbar degenerative diseases. One limitation to this study is that it is a non-randomized study. Further studies need to be done in a randomized, prospective manner, with respect to long-term clinical outcomes.

\section{Materials And Methods}

Our study is part of a multi-centre prospective, case-controlled study in Egypt to determine the safety and efficacy of minimally invasive spinal procedures; of these, the Coflex implant, a functionally dynamic interspinous implant (U-shaped titanium), is included in the present study. From June 2008 until July 2013, we treated 42 patients with this Coflex procedure. Median follow-up was 22.5 months. At the time of followup, all patients completed questionnaires and underwent clinical examination and radiography.

The Scientific Committee of the Department of Neurosurgery, Faculty of Medicine, Cairo University issued approval for this study. Informed patient consent was obtained for all patients.

\section{Patient selection}

The inclusion criteria were patients at 40 -years of age or older with leg, buttock, or groin pain and with or without back pain that could be relieved during flexion. Neurogenic claudication should be an integral part of the patient's complaint. Patients had to have completed at least three to six months of non-operative treatment with no improvement. Stenosis was confirmed by CT or MRI scans at one or two levels. Primary exclusion criteria included a fixed motor deficit, cauda equina syndrome, frank instability, previous lumbar surgery, significant peripheral neuropathy, scoliosis, pathological fractures, severe osteoporosis, obesity, active infections, active systemic disease, or vertebral metastasis.

\section{Evaluation and outcomes assessment}

Data was collected preoperatively and postoperatively at four weeks, six months, one year, and three years following the initial treatment. Patients were asked to grade their low back and leg pain using the numeric verbal rating (NVR) scale for pain [3]. Patients were asked about their satisfaction with the surgical procedure using the validated outcome measurement specific to lumbar spinal stenosis, namely, the Oswestry Disability Index Questionnaire (ODI) [21-23].

Using the numeric verbal rating (NVR) scale for pain intensity, significant relief was defined as pain relief of $50 \%$ or greater; otherwise, it was non-significant (less than $50 \%$ ). Significant pain relief included patients in the pain-free and improved pain categories, while non-significant pain relief included patients in the fair and bad categories. Duration of pain relief was judged to be short-term if relief was less than six months. If relief lasted for at least six up to 12 months, it was considered long-term. Success was defined as all of the following: 1) no pain or minimal remaining pain; 2) work not adversely affected; 3) no use of analgesic medications; and 4) patient satisfaction with the procedure [21,23].

ODI scoring $0 \%$ to $20 \%$ means minimal disability (patient can cope with most living activities, no treatment is indicated apart from exercise), $21 \%-40 \%$ moderate disability (patient experiences more pain and difficulty with sitting, lifting, and standing, patient managed by conservative means), $41 \%-60 \%$ severe disability (pain remains the main problem, activities of daily living are affected, requires a detailed investigation), $61 \%-80 \%$ crippled (back pain impinges on all aspects of the patient's life, intervention is required), and $81 \%-100 \%$ are either bed-bound or exaggerating their symptoms [22-23].

At each follow-up visit, pain and function evaluations were performed to confirm the absence of complications. Clinical outcome scores and incidence rates of adverse effects, device failures, and revision surgeries, if any, were calculated.

\section{Imaging interpretation}

Postoperatively, a follow-up MRI scan was done at six months. X-rays were done at one week, three months, and at yearly visits. Follow-up X-rays were analyzed to confirm maintenance of distraction and the absence of device-related radiological complications. The changes in the disc height, endplate angles, and dynamic lumbar movement were assessed before and after the placement of the Coflex ${ }^{\circledR}$ implant. Distances were measured between the most anterior or posterior points on each vertebral body, excluding osteophytes. Endplate angles and foraminal height were measured. Endplate angles were measured on the images between adjacent vertebral bodies at the treated level.

\section{Procedure}

The devices were implanted by, or under the direct supervision of, a single surgeon. The patients had the procedure under a light general anesthetic. Patients were placed on a radiolucent table in the prone position, on a surgical frame avoiding hyperlordosis of the spinal segment(s) to be operated upon. A neutral position or a slight kyphosis may be advantageous for surgical decompression as well as for appropriate interspinous distraction. The level to be treated was identified by fluoroscopy. Routine (midline) skin 


\section{Cureus}

incision of approximately $3 \mathrm{~cm}$ (per level), was performed over the spinous processes of the stenotic level(s) (Figure 1). This was carried down to the fascia, which was split longitudinally $1 \mathrm{~cm}$ to the right and 1 $\mathrm{cm}$ to the left of midline. It was extremely important to keep the supraspinous ligament intact. The muscle was sharply dissected to the level of laminae and facets, lateral to the supraspinous ligament, preserving the entire thickness of the supraspinous ligament and the facet capsules. If possible, a small portion of the spinous bony tip can be resected together with the supraspinous ligament. This aided in a faster healing after reconstruction of the ligament. The interspinous ligament was removed; any bony overgrowth of the spinous process that may interfere with insertion was resected.

After preparation of the implantation site, trial instruments are utilized to define appropriate implant size, evaluate proper contact with spinous process and amount of interspinous distraction. Some bony resection of the spinous process may be needed to ensure proper contact of the implant. To ensure proper depth of implant insertion, a small portion of the laminar surface may need partial resurfacing. The implant wings may need to be opened slightly using bending pliers at the mid-portion of the wing to ensure appropriate depth of insertion. Implant is then introduced via impaction utilizing a mallet. Proper depth is determined if a beaded tip probe can be passed freely leaving $3-4 \mathrm{~mm}$ separation from the dura. If the implant is not seated appropriately further resurfacing or slightly more impaction force may be utilized. If the wings are not having sufficient bony contact, additional stability can be achieved by slightly crimping the wings. Anteroposterior and lateral fluoroscopy views are taken to verify the proper position. The incision is closed in the usual fashion. The drain is not routinely utilized. The procedure is typically performed in less than an hour. Postoperatively, patients were mobilized immediately once they had recovered from the effects of any anesthetic or sedation and discharged within two days, with external brace for four weeks postoperatively.

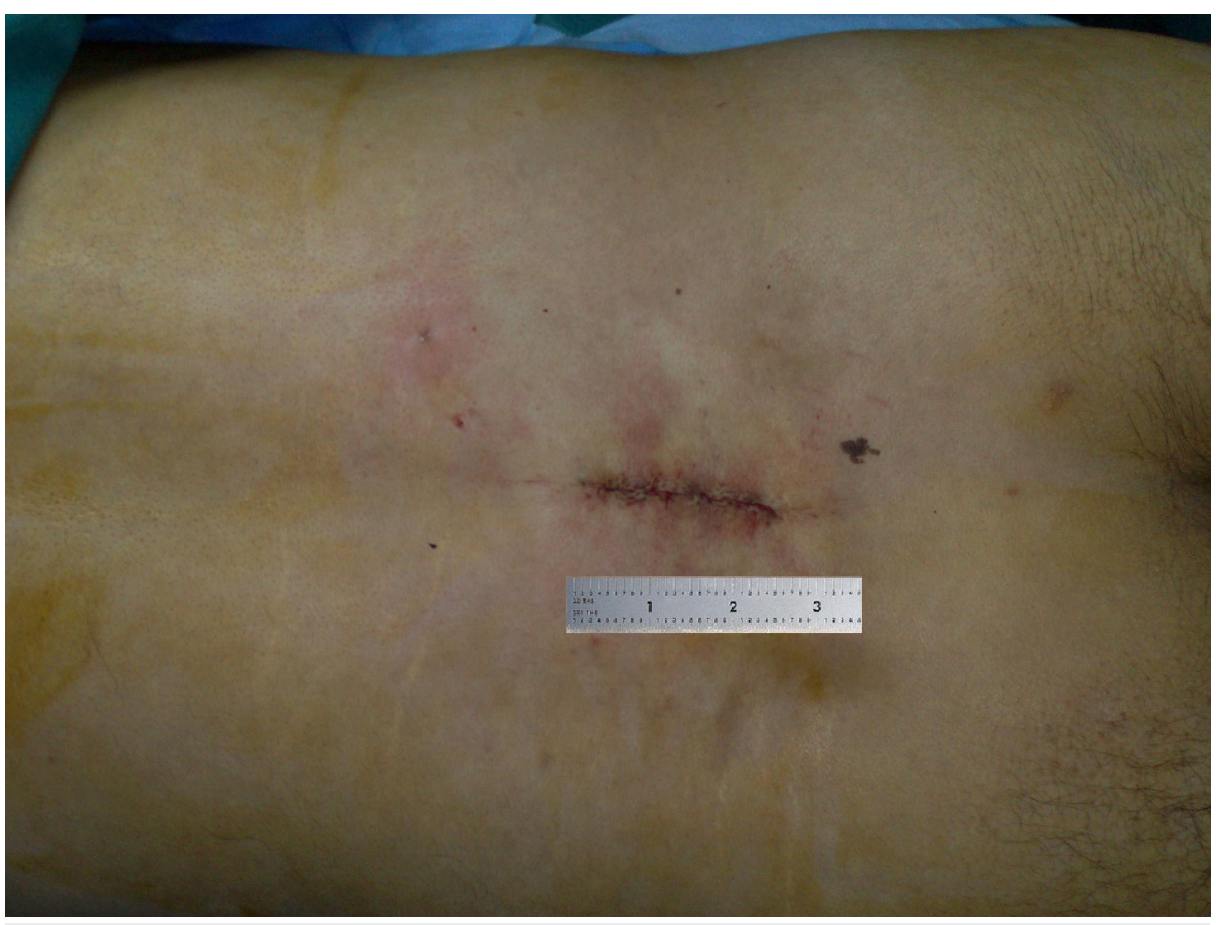

FIGURE 1: Routine (midline) skin incision of approximately $3 \mathrm{~cm}$ (per level) is performed over the spinous processes of the stenotic level(s)

\section{Results}

From June 2008 until July 2013, 42 patients with degenerative spinal stenosis were treated with the Coflex procedure, 18 (43\%) male, 24 (57\%) female. The average length of follow-up was 22.5 months (range 13 to 44) and the average age at the time of the operation was 45 years (range 40 to 70 ). Thirty-six out of 42 patients had the Coflex implanted at one level (mainly L3-4 or L4-5). There were six implantations at the L5S1 level in the study. Six out of 42 patients had the Coflex device implanted at two levels (L3-4 and L4-5). Thirty out of 42 patients in the study had a segmental form of stenosis (discogenic, ligamentous, bony, or mixtures), nine cases had a mild degree of degenerative retrolisthesis, and three cases had mild first degree of degenerative spondylolisthesis.

A significant number of patients showed pain relief. Preoperatively, 30/42 (71\%) patients presented with moderate or severe low back pain (LBP). Postoperatively, the LBP in six (14\%) patients did improve and 24 (57\%) even showed no low back pain anymore. Mean preoperative walking distance was $<1000 \mathrm{~m}$ in $36(86 \%)$ 


\section{Cureus}

patients. Postoperatively, 42 (100\%) patients could walk $>1000 \mathrm{~m}$. Significant pain relief $(>50 \%)$ in months was calculated. The short-term pain relief outcome, which was assessed six months after the operation, indicated a success rate (significant pain relief) of 93\%. However, late follow-up which was assessed 12 months after the operation indicated a success rate of $97 \%$. Significant pain relief was manifest. The results of pain relief throughout the study were best at late follow-up visits. Follow-up visits did show an increase of patient satisfaction. Thirty-nine patients (93\%) stated that they would undergo this surgery again. According to the questionnaires, 39 (93\%) patients were satisfied or very satisfied; only three patients (7\%) were not totally satisfied. The mean preoperative ODI score was 55 (range 30 to 80 ). The mean postoperative ODI score was 10 (range 0 to 30 ).

Immediate postoperative complications occurred in nine (21\%) patients, (three seromas and six worsening of existing numbness). All were temporary. One patient had the Coflex removed due to traumatic fracture of the spinous process. No broken, deformed, or migrated Coflex was found. No patients needed further fusion within one year postoperatively; three patients presented with recurrent disc herniation.

\section{Radiological results}

1. Endplate angles: As seen in Fig., when were acute preoperatively, always become less acute postoperatively, and the foraminal height always increases.

2. Segmental ROM: Postoperative flexion and extension views showed maintenance of the dynamic movements at the operated level.

3. Disc height: Fig showed significant changes after the procedure in both anterior and posterior disc heights.
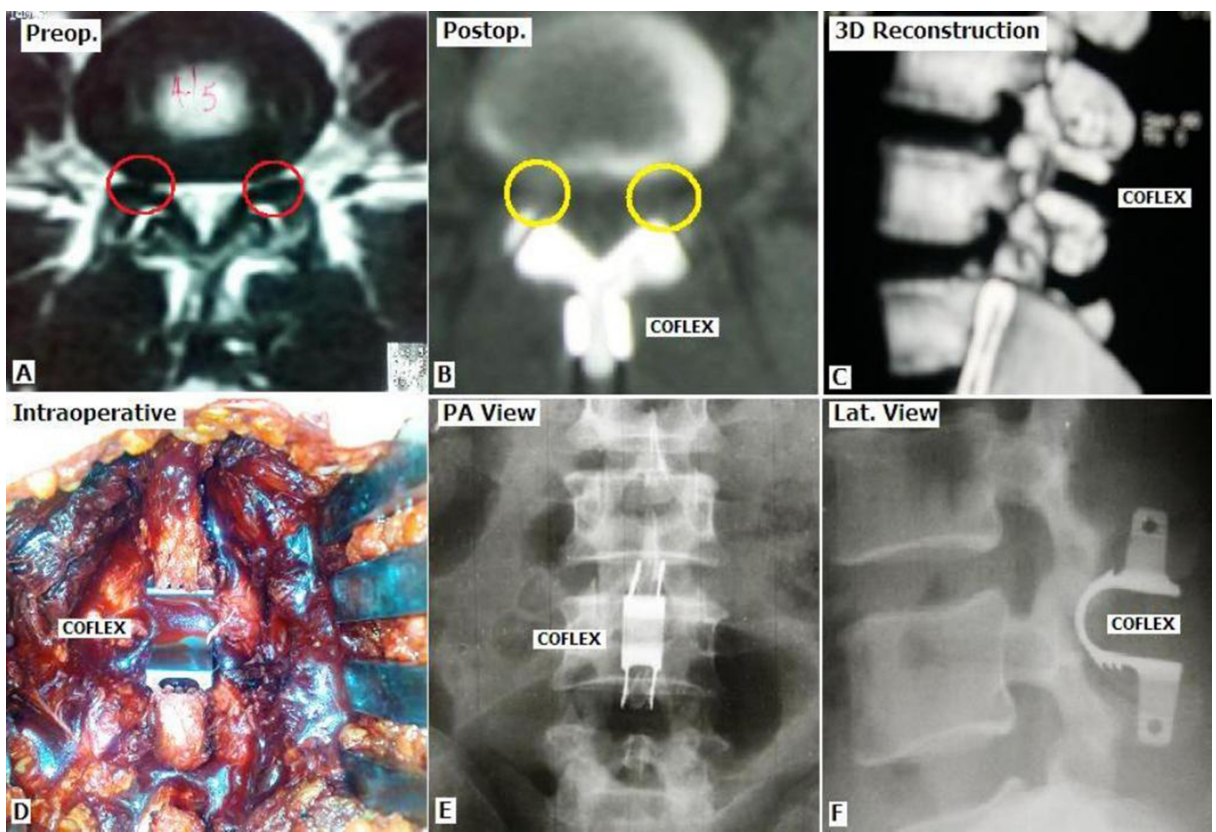

PA View
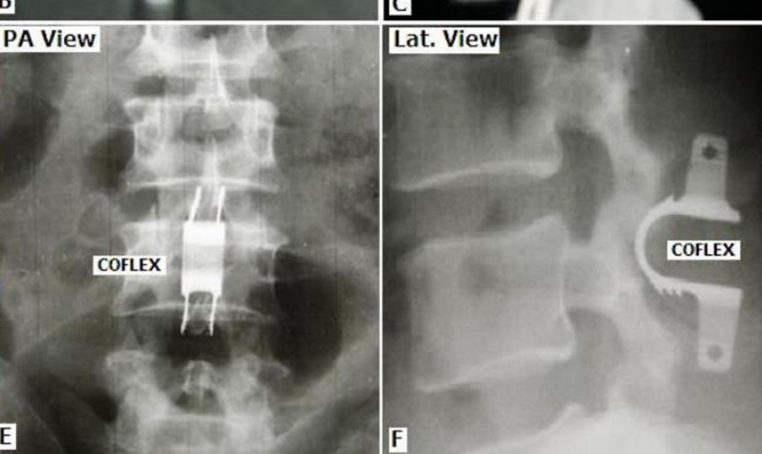

FIGURE 2: Preoperative bilateral foraminal narrowing is shown to widen postoperatively by the interspinous distraction Coflex device.
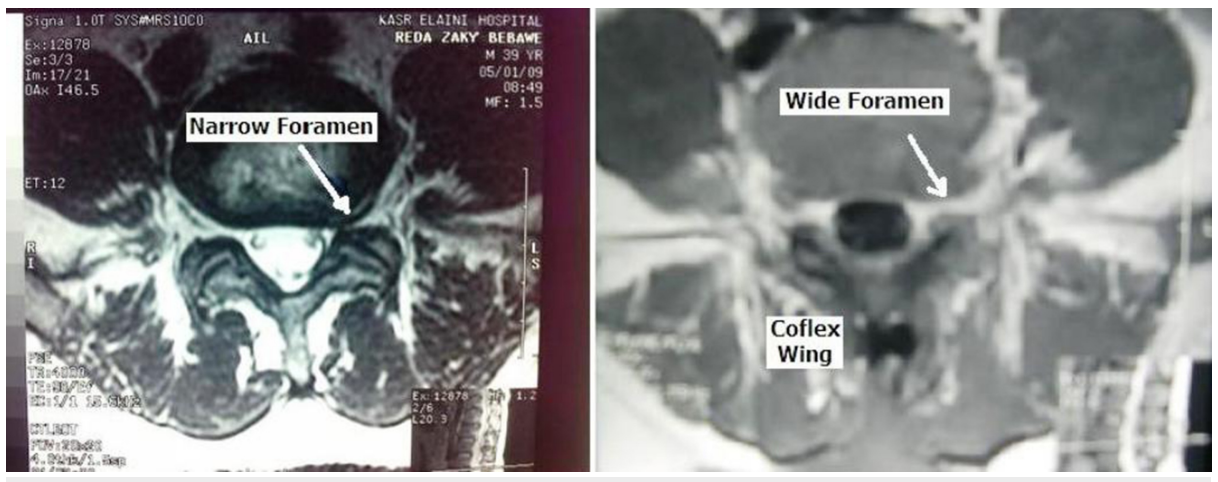


\section{Cureus}

FIGURE 3: Preoperative unilateral foraminal narrowing is shown to widen postoperatively

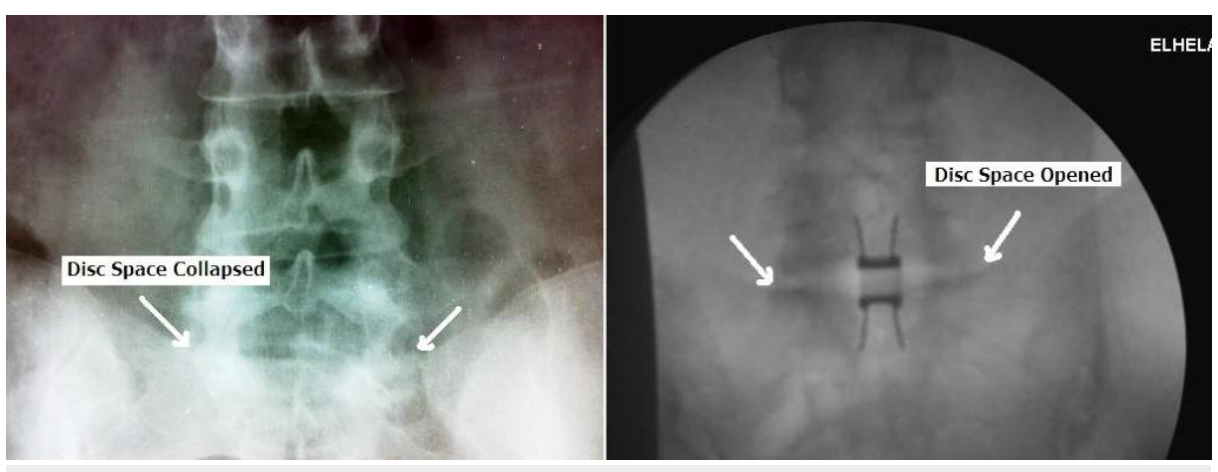

FIGURE 4: Collapsed disc space is obviously opened by Coflex.

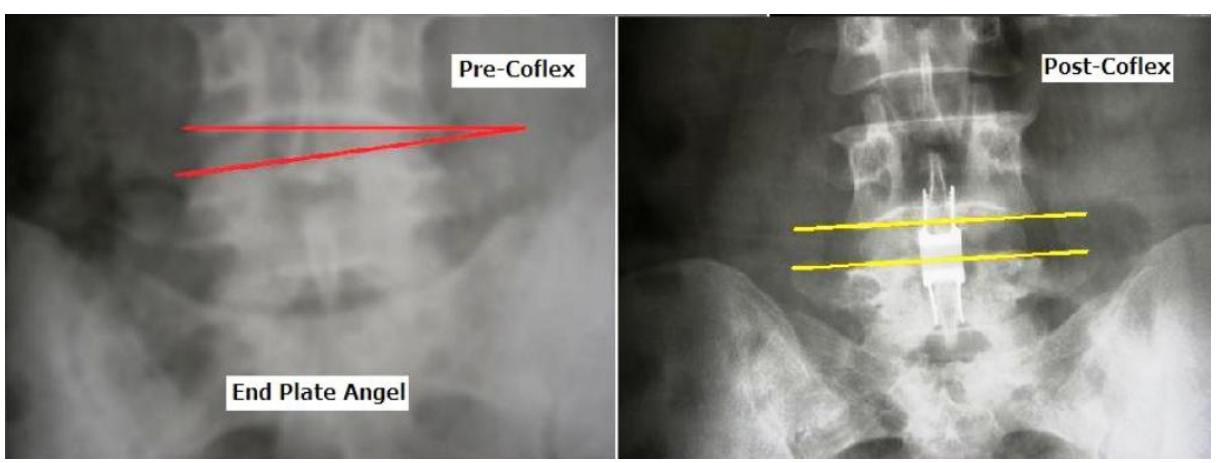

FIGURE 5: The AP endplate angle deviation is corrected postoperatively.

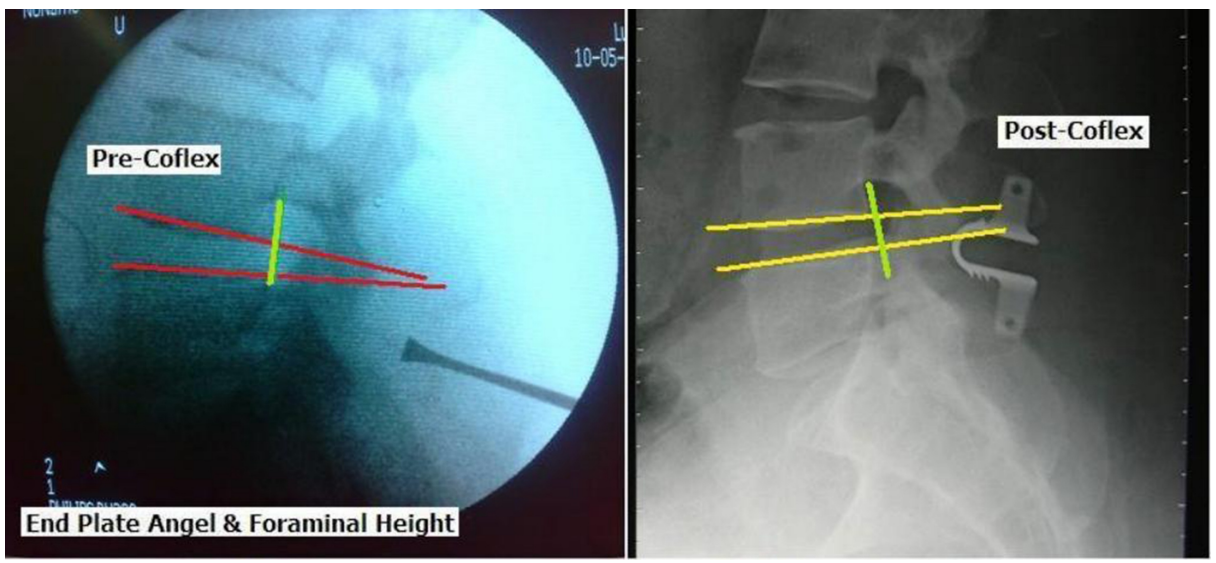

FIGURE 6: The lateral endplate angle and foraminal height are corrected postoperatively. 


\section{Cureus}

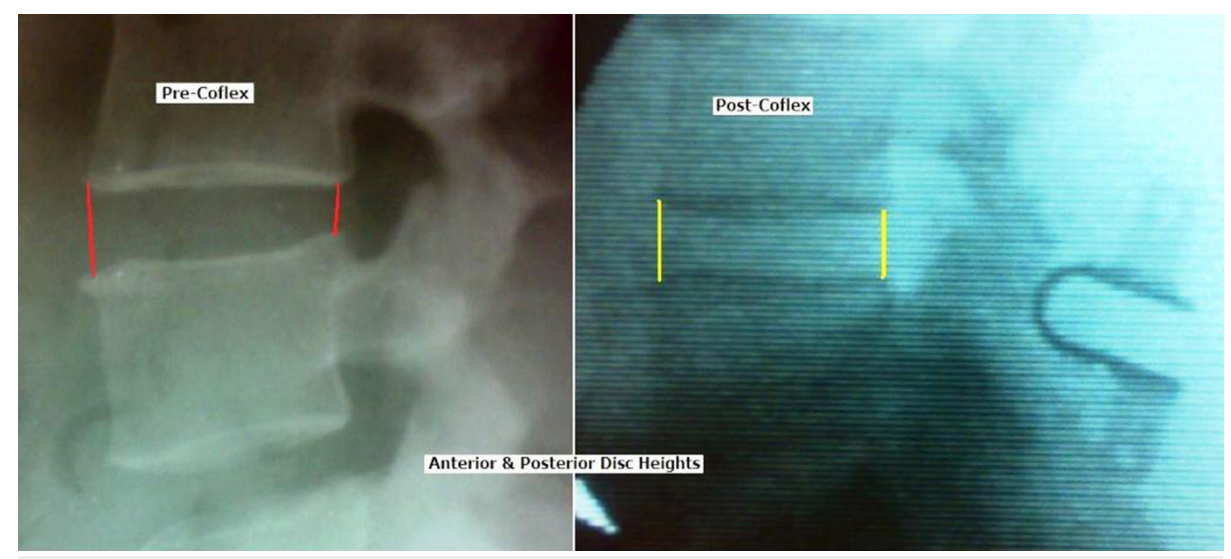

FIGURE 7: Anterior and posterior disc heights pre- and postoperatively.

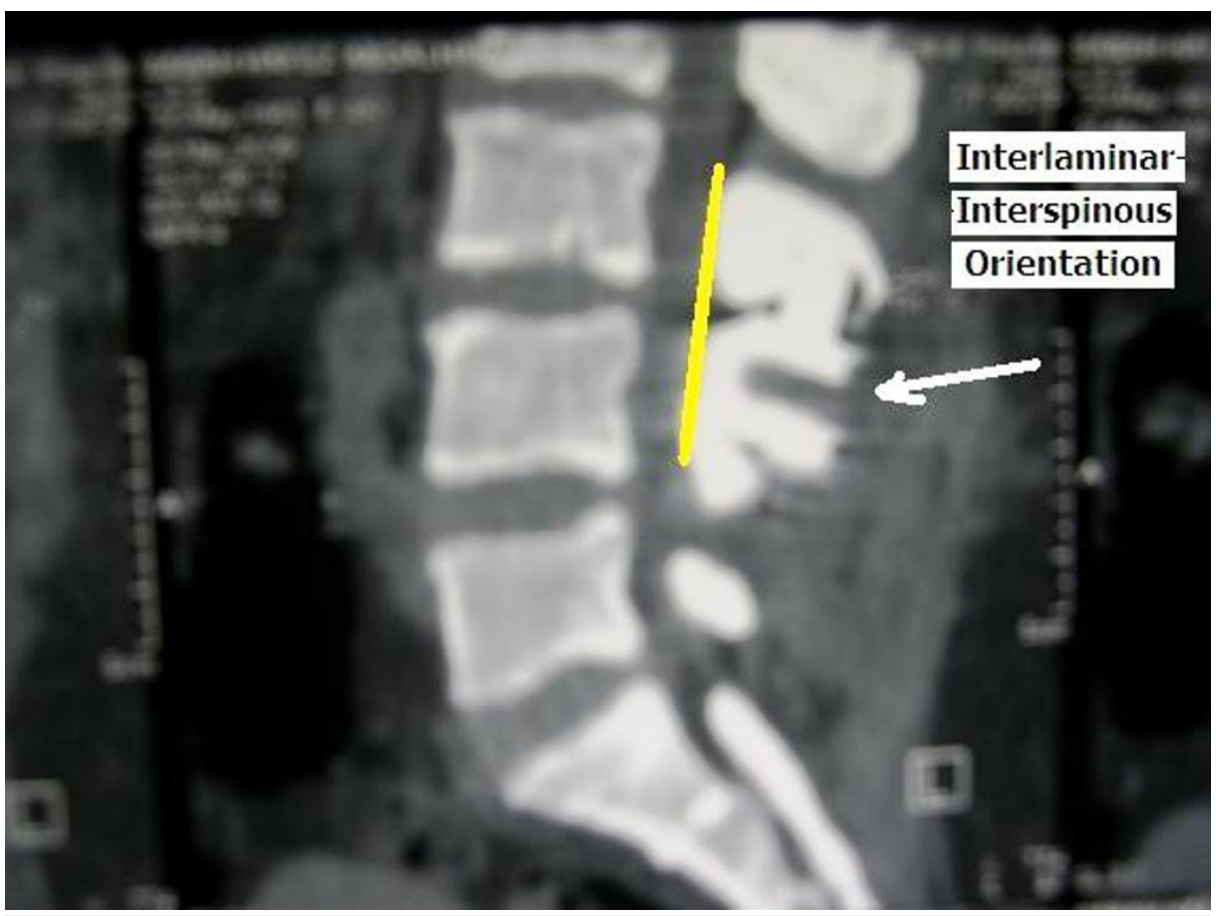

FIGURE 8: The Coflex has an interlaminar orientation. 


\section{Cureus}
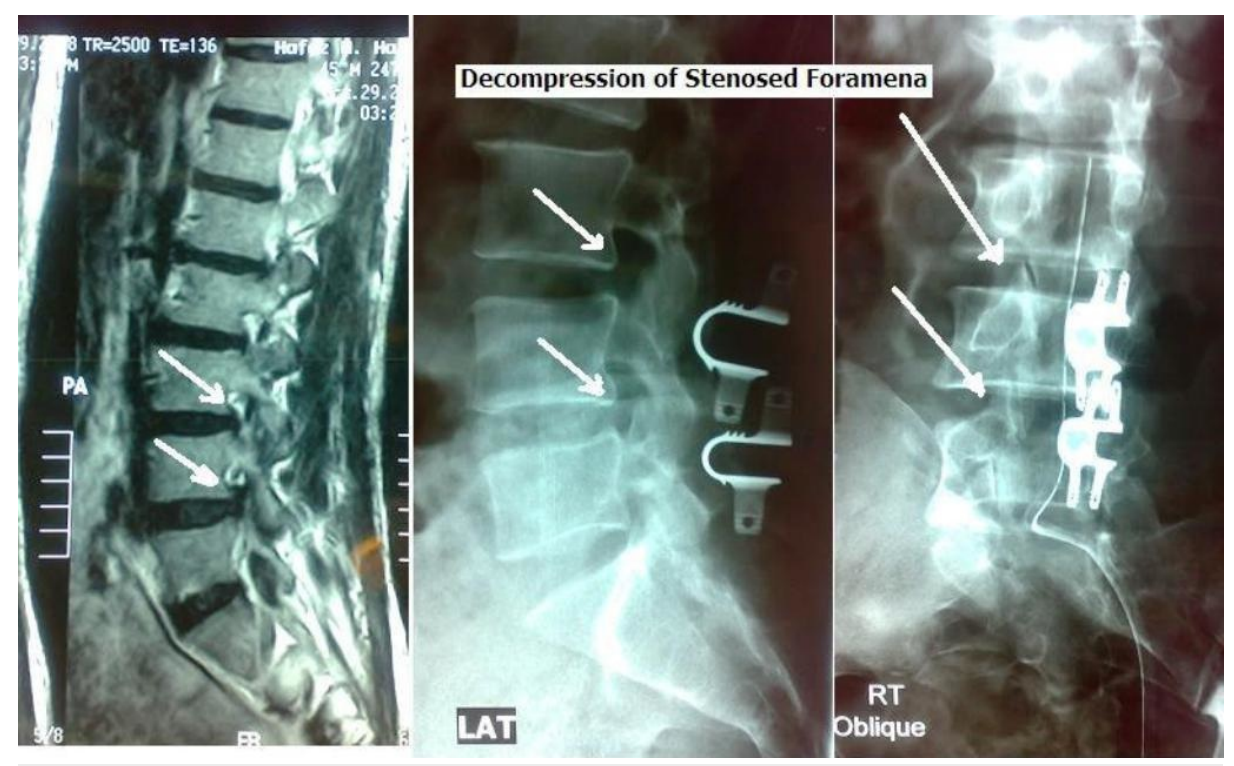

FIGURE 9: Stenosed foramina are obviously decompressed.

\section{Discussion}

It is well understood that flexion relieves the symptoms of LCS and extension aggravates the symptoms. In the literature, it is well demonstrated that the pain relief is a result of an increase in the dimensions of the canal and foramen. Thus, interspinous distraction devices was conceived as providing effective pain relief for LCS patients by placing the stenotic level mechanically in slight flexion and restricting extension [21-23].

The Coflex ${ }^{\circledR}$ DIDS device is a relatively new, but well-documented motion-preserving spinal procedure. The Coflex ${ }^{\circledR}$ DIDS device has been designed to treat patients with neurogenic intermittent claudication. It is a titanium U-shaped spacer placed between the two adjacent spinous processes of the affected level. The migration of the implant is prevented by rough contact surfaces to minimize expulsion, together with wings attached to the spacer, and the bony margins of the spinous processes cranially, and caudally, controlling rotation; assuring spinal alignment; and aiding in preventing expulsion [24-33].

Clinically, our results about the use of the Coflex ${ }^{\circledR}$ DIDS device in DDLS, especially LCS, matches concurrent results in the recent literature to be safe and effective in relieving patient's symptoms [25, 28, 30, 33]. This study confirmed the known positive effect of distraction decompression of neural structures on claudication and leg pain. In addition, the moderate and/or severe LBP could be relieved in $71 \%$ of the patients.

Regarding the walking distance measured in the current study, it is clear that the performance of the Coflex patients compares favorably to that of patients undergoing all other surgical decompression procedures. The decreased preoperative walking distance, partly due to LBP, partly due to claudication, improved significantly. Also, the patient satisfaction was extremely high (up to 100\%) and the majority (93\%) would undergo surgery again. The rate of complications in our study was very low, and all temporary. There was no implant related complications.

The Coflex ${ }^{\circledR}$ DIDS device, positioned interlaminarly, close to the anatomical centre of rotation (COR) and reaching the level of the facet joints, the range of motion of the facet joints can be controlled, the joint is slightly distracted, the foraminal height is restored and due to the metallic stiffness the height will be maintained (Figures 3, 6). Thus, the implant causes interspinous and discal distraction; center of rotation being interlaminar, and compressible in extension; it puts the stenotic segment in flexion and resists extension, keeping dynamic motion intact (Figure 2) (Figures 4, 5) (Figure 7). Our radiological results showed that the posterior disc height did show a postoperative maintained increase, irrespective of posture and number of operated levels, with no change over follow-up visits. Moreover, we did see a significant reduction in the acuteness of the endplate angels, and an apparent increase in the foraminal height of the distracted segments. Dynamic motion was preserved in all cases, with limitation of full flexion. Also, this study demonstrated that by distracting the interspinous processes the Coflex spacer increased the dimensions of the spinal canal and neural foramina at the implanted level in extension, but it did not alter the dimensions of the adjacent, intact levels in the extended, flexed, or neutral positions [25, 28, 30, 33].

Procedural aspects of Coflex implantation also add to the safety and effectiveness of the procedure. It is an easy, rapid, minimally invasive approach, with no reported complications. None of the complications reported in the literature for related surgeries, as those of Benz, et al. (intraoperative complications, such as dural tears, and postoperative complications, such as wound infection, pneumonia, and epidural 
hematoma), were observed during or after the Coflex procedure. No recurrence of symptoms was reported [24-28].

Merging the clinical and radiological results of the current study suggest that these effects produce a clinical benefit for LCS patients treated with the Coflex spacer. Though this series has limitations of a smaller sample size, it nevertheless confirms the satisfactory results. We will continue to follow the patients enrolled in this study, together with new cases and will report on the longer follow-up.

\section{Conclusions}

The current study provides evidence that immediate pain relief and increase in function can be provided by the Coflex Device with a low rate of morbidity. It is considered a minimally-invasive armamentarium in the scope of managing lumbar degenerative diseases, especially LCS.

\section{Additional Information}

\section{Disclosures}

Human subjects: Consent was obtained by all participants in this study. The Scientific Committee of the Department of Neurosurgery, Faculty of Medicine, Cairo University issued approval N/A. Animal subjects: All authors have confirmed that this study did not involve animal subjects or tissue. Conflicts of interest: In compliance with the ICMJE uniform disclosure form, all authors declare the following: Payment/services info: All authors have declared that no financial support was received from any organization for the submitted work. Financial relationships: All authors have declared that they have no financial relationships at present or within the previous three years with any organizations that might have an interest in the submitted work. Other relationships: All authors have declared that there are no other relationships or activities that could appear to have influenced the submitted work.

\section{References}

1. Leone A, Guglielmi G, Cassar-Pullicino VN, Bonomo L: Lumbar Intervertebral Instability: A Review . Radiology. 2007, 245:62-77.

2. Fujiwara A, Lim TH, An HS, et al.: The effect of disc degeneration and facet joint osteoarthritis on the segmental flexibility of the lumbar spine. Spine. 2000, 25:3036-3044.

3. Fujiwara A, Tamai K, An HS, et al.: The relationship between disc degeneration, facet joint osteoarthritis, and stability of the degenerative lumbar spine. J Spinal Disord. 2000, 13:444-450.

4. Miyasaka K, Ohmori K, Suzuki K, Inoue H: Radiographic analysis of lumbar motion in relation to lumbosacral stability. Spine. 2000, 25:732-737.

5. Berlemann U, Jeszenszky DJ, Buhler DW, Harms J: Mechanism of retrolisthesis in the lower lumbar spine: A radiographic study. Acta Orthop Belg. 1999, 65:472-477.

6. Axelsson P, Karlsson BS: Intervertebral mobility in the progressive degenerative process: a radiostereometric analysis. Eur Spine J. 2004, 13:567-572.

7. van Tulder MW, Assendelft WJ, Koes BW, Bouter LM: Spinal radiographic findings and nonspecific low back pain: A systematic review of observational studies. Spine. 1997, 22:427-434.

8. Pitkanen MT, Manninen HI, Lindgren KA, Sihvonen TA, Airaksinen O, Soimakallio S: Segmental lumbar spine instability at flexion-extension radiography can be predicted by conventional radiography. Clin Radiol. 2002, 57:632-639.

9. Nizard RS, Wybler M, Laredo JD: Radiologic assessment of lumbar intervertebral instability and degenerative spondylolisthesis. Radiol Clin North Am. 2001, 39:55-71.

10. Wilke HJ, Drumm J, Häussler K, Mack C, Steudel WI, Kettler A: Biomechanical effect of different lumbar interspinous implants on flexibility and intradiscal pressure. Eur Spine J. 2008, 17:1049-1056. 10.1007/s00586-008-0657-2

11. Amundsen T, Weber H, Nordal HJ, Magnaes B, Abdelnoor M, Lilleas F: Lumbar spinal stenosis: Conservative or surgical management?: A prospective 10-year study. Spine. 2000, 25:1424-1436.

12. Christie SD, Song JK, Fessler RG: Dynamic interspinous process technology. Spine. 2005, 30:S73-S78.

13. Lindsey DP, Swanson KE, Fuchs P, Hsu KY, Zucherman JF, Yerby SA: The effects of an interspinous implant on the kinematics of the instrumented and adjacent levels in the lumbar spine. Spine. 2003, 28:2192-2197.

14. Minns RJ, Walsh WK: Preliminary design and experimental studies of a novel soft implant for correcting sagittal plane instability in the lumbar spine. Spine. 1997, 22:1819-1827.

15. Schmoelz W, Huber JF, Nydegger T, Dipl I, Claes L, Wilke HJ: Dynamic stabilization of the lumbar spine and its effects on adjacent segments: An in vitro experiment. J Spinal Disord Tech. 2003, 16:418-423.

16. Swanson KE, Lindsey DP, Hsu KY, Zucherman JF, Yerby SA: The effects of an interspinous implant on intervertebral disc pressures. Spine. 2003, 28:26-32.

17. Whitesides TE Jr: The effect of an interspinous implant on intervertebral disc pressures . Spine. 2003, 28:1906-1908.

18. Wiseman CM, Lindsey DP, Fredrick AD, Yerby SA: The effect of an interspinous process implant on facet loading during extension. Spine. 2005, 30:903-907.

19. Tsai KJ, Murakami H, Lowery GL, Hutton WC: A biomechanical evaluation of an interspinous device (Coflex ${ }^{\mathrm{TM}}$ Device) used to stabilize the lumbar spine. Paradigm Spine Journal. 2006, 1:1-4.

20. Hsu KY, Zucherman JF, Hartjen CA, Mehalic TF, Implicito DA, Martin MJ, Johnson DR 2nd, Skidmore GA, Vessa PP, Dwyer JW, Cauthen JC, Ozuna RM: Quality of life of lumbar stenosis-treated patients in whom the X STOP interspinous device was implanted. J Neurosurg Spine. 2006, 5:500-7.

21. Ware J, Epps C, Herr K, Packard A: Evaluation of the revised faces pain scale, verbal descriptor scale, 
numeric rating scale, and Iowa pain thermometer in older minority adults. Pain Manag Nurs. 2006, 7:117125.

22. Fairbank JC, Pynsent PB: The Oswestry Disability Index. Spine. 2000, 25:2940-2952.

23. Stucki G, Daltroy L, Liang MH, et al.: Measurement properties of a self-administered outcome measure in lumbar spinal stenosis. Spine. 1969, 21:796-803.

24. Anderson PA, Tribus CB, Kitchel, SH: Treatment of neurogenic claudication by interspinous decompression: application of the X STOP device in patients with lumbar degenerative spondylolisthesis. J Neurosurg, Spine. 2006, 4:463-471.

25. Kaech DL, Fernandez C, Lombardi-Weber D: The interspinous 'U': A new restabilization divide for the lumbar spine. Spinal Restabilization Procedures. Kaech DL, Jinkins JR (ed): Elsevier Science, Amsterdam; 2002. 355-362.

26. Christie SD, Song JK, Fessler RG: Dynamic interspinous process technology. Spine. 2005, 30:S73-78.

27. Dubois G, De Germay B, Schaerer NS, et al.: Dynamic neutralization: A new concept for restabilization of the spine. Lumbar Segmental Instability. Szpalski M, Gunzburg R, Pope MH (ed): Lippincott \& Wilkins, Philadelphia; 1999. 233-240.

28. Lumbar non-fusion posterior stabilisation devices . (2008). Accessed: $1 / 1 / 14$ http://www.msac.gov.au/internet/msac/publishing.nsf/Content/app1099-1.

29. Atlas SJ, Keller RB, Wu YA, Deyo RA, Singer DE: Long-Term outcomes of surgical and nonsurgical management of lumbar spinal stenosis: 8 to 10 year results from the Maine lumbar spine study. Spine (Phila Pa 1976). 2005, 30:936-43.

30. Doo-Sik K, Eun-Sang K, Whan E: One-year outcome evaluation after interspinous implantation for degenerative spinal stenosis with segmental instability. J Korean Med Sci. 2007, 22:330-5.

31. Kondrashov DG, Hannibal M, Hsu KY, Zucherman JF: Interspinous process decompression with the X-STOP device for lumbar spinal stenosis. A 4-year follow-up study. J Spinal Disord Tech. 2006, 19:323-327.

32. Kim KA, McDonald M, Pik JH, et al.: Dynamic intraspinous spacer technology for posterior stabilization: Case-control study on the safety, sagittal angulation, and pain outcome at 1-year follow-up evaluation. Neurosurg Focus. 2007, 22:E7.

33. Dieter A, Jacques S, Woo-Kyung K, et al.: Coflex ${ }^{\circledR}$ Interspinous Stabilization: Clinical and Radiographic Results from an International Multicenter Retrospective Study. Paradigm Spine Journal. 2007, 1:1-4. 